\title{
LEARNING FROM THE PAST TOWARD ENERGY RESILIENT STRATEGIES IN HISTORIC DISTRICTS. A CASE STUDY IN APULIA REGION (ITALY)
}

\author{
E. Cantatore $^{1 *}$, F. Fiorito ${ }^{1}$, F. Fatiguso ${ }^{1}$ \\ ${ }^{1}$ Polytechnic of Bari, 70126 Bari BA, Italy - (elena.cantatore, francesco.fiorito, fabio.fatiguso)@ poliba.it
}

Commission II - WG II/8

KEY WORDS: Resilience, Historic Districts, Energy retrofit, Mediterranean area

\begin{abstract}
:
The high exposure of future changes in temperature trends in the southern part of Mediterranean area encouraged scientific community in defining strategies aiming at the reduction of cooling needs as short and long-term goals. Furthermore, local urban properties and their transformation contribute in altering microclimate at the micro-scale. Focus on a specific part of urban built stock, historic districts represent an exception in managing processes of recovery and energy retrofit strategies due to their landscape values; moreover, these districts show their recent transformations caused by the previous abandonment phase and, often, consequent loss of blocks. In that context, the paper shows the representative case study of historic district of Molfetta, in Apulia region (Italy): here, the energy assessment takes into account the effect of the abandonment of the district during $60 \mathrm{~s}$ on the in use residential built stock in a temporalclimate prediction. As it was well demonstrated in previous experiences, strategies for the energy retrofit of residential buildings in historic district should allow to identify their inherent bioclimatic behaviours according with the genius loci evidences; furthermore, recognize and correct previous failures represent the opportunity to "learn from the past" in the "resilient thinking" process, above all after traumatic events.
\end{abstract}

\section{INTRODUCTION}

Currently the assessment and the characterization of the effects of climate change represent the main focus of scientific research and political debate all over the world (Bhandari, 2015; Gotham, Faust, 2020; Grafakos et al., 2020; Steynor et al., 2020; Yun et al., 2020). In Europe, the attention is focused on the Mediterranean area because of its high exposure to future events, like increase of maximum temperatures and frequency of heat waves (Coppola, Giorgi, 2010; Parry, 2007). Causality analyses are mainly concentrated on cities, as areas where human health, comfort and security could be compromised. European and national strategies aimed at climate change mitigation are mainly concentrated on urban areas, and within them, on residential building stock. The most studied strategy to cope with climate change in existing residential buildings is related to energy retrofit with the aim of both improving the external envelope performance - as a passive strategy - and building services - as active strategy - towards the nearly Zero Energy Building (nZEB) goal (EPBD, 2010). In parallel, the uncertainty related to future climatic scenarios affected by a combination of economic and population growth, has led to the introduction of strategies aimed at the analysis, characterization and strengthening of adaptive features of urban environment. (European Commission, 2013). So, merging the themes of uncertainties and adaptability, priority and risk exposure has become the key themes of the widespread strategies aimed at the analysis of urban environment in a long perspective.

A specific objective of most of the research activities is the analysis of districts characterized by high rainwater runoff, dark surfaces, high density of buildings, low greenery percentages and high level of anthropic emissions. The combination of all those parameters alters urban microclimate, enhancing the well-known phenomenon of Urban Heat Island (UHI) (Mohajerani et al., 2017; Santamouris et al., 2011). Moreover, another forcing element for the development of UHI is represented by the energy dispersions towards outdoor, flowing through the fabric of old residential buildings built before the implementation of the first energy codes. Inner urban areas, like historic districts, are so far mostly excluded from the energy strategies mentioned before. Those districts include, however, a relevant portion of European building stock, as more than $19 \%$ of existing building were built before the 1919 (Troi, 2011), and constitute a critical element in the process management of cities' transformation because of their cultural relevance (ICOMOS, 2011). Indeed, for historic districts, as well as for all the heritage-listed buildings, persistence and preservation are the priority and predominant characters in the whole process of their management, from analysis to definition of transformation solutions, both for mitigation and adaptation goals. Previous European experiences on cultural heritage management (e.g. Climate for Culture), and as a direct consequences of European and national directives in adaptive management (Castellari et al., 2014), have underlined the need to assess the risk exposure to climate change. Continuous monitoring, frequent routine maintenance actions, and definition of intervention priorities are some of the strategies that have been identified. By combining the concepts of persistence, adaptability and transformability, the concept of resilience has been introduced by Walker (Walker et al., 2004). When resilience is applied to the cultural heritage, it has to account for the ethical responsibility of community in preserving all the values that each historic case represents. Focusing on cultural heritage retrofit and on resilient design strategies (Correia et al., 2014; Tyler, Moench, 2012), knowledge and capacity to learn are assonant criteria.

It is also well accepted by the scientists and cultural community that traditional buildings are the result of a slow process of onsite experimenting of techniques and codes of good practices towards the satisfaction of human needs, health, well-being and security (Guillaud, 2014). From the application of these

\footnotetext{
* Corresponding author
} 
techniques and good practices derived socio-cultural, socioeconomic and environmental values of built heritage. However, these buildings represent also the result of several transformation actions not strictly related to the genius loci experience. Instead, these interventions often represent the final effect of the need to cope with functional and technological obsolescence of buildings and their components, when overarching administrative instruments of control are missing. However, this process must be associated with the slow abandonment of the historic centres, which happened in Italy during the XX century. This process was the result of the combination of low state of conservation, as well as the sanitary conditions of historic centres and the economic and construction growth. In fact, during the 1960s, the population of the historic centres - both large and minor ones (Falini, 1978) - moved towards new suburban areas. Cultural relevance and extension of some ancient cities encouraged administrative offices in defining strategies and integrated actions for their refurbishment and improvement, also under the energy point of view. However, large sub-urban historical areas remain in severe management and conservative emergency; this is the case of sprawling old town of Palermo (Cannarozzo, 2007; Diappi, 2009), of some UNESCO heritage sites (Fatiguso et al., 2017), but also of some minor cases in the Apulia region (Fatiguso et al., 2016). For some of these, the issue of both formal and sanitary recovery, as well as energy-performance, can be considered a priority at all levels.

The present paper is included in the framework described before and is a part of a wider research aimed at the definition of an energy-resilient methodology for the retrofit of historic districts, joining criteria of the resilient thinking with the traditional process of recovery applied to Cultural Heritage. Moreover, the present work highlights the relevance of knowledge as the first part of methodological framework, focusing on the abandonment phenomenon that represents, until now, a peculiar characteristic of some Italian historic districts.

\section{METHODOLOGY AND TOOLS}

As it has been already stated in the previous paragraphs, the methodology aimed at the assessment of the energy impact, caused by the abandonment of several buildings, of the residential building stock within historic centres. In detail, the assessment derived from the knowledge process in which historic processes of development and abandonment phases, as well as the recognition of inherent qualities, are analysed. Here, the energy impact is the result of a comparative assessment of several representative buildings. Each of the building has variable boundary conditions depending on the state of maintenance, on the use and on future climate trends.

DesignBuilder $($ ) software has been used in order to predict energy consumption of buildings subject to the previously mentioned variable boundary conditions. DesignBuilder is a thermal dynamic simulation tool - based on the EnergyPlus engine - that allows to predict the energy consumption of buildings, also accounting for the mutual shading effect between buildings and building complexes. That option is fundamental for districts featured by high density as the historic ones.

In order to solve the temporal assessment, energy simulator requires the use of representative local climate data file and their future projections, generated according to the analysis supported by the Intergovernmental Panel on Climate Change (IPCC). In detail of them, IPCC introduced the scenarios as "story-lines", dividing them in four types defined as complex combinations of driving forces involved in future GHG variations - demographic and socio-economic development and technological change (Nakicenovic et al., 2000). Meteonorm tool has been selected to generate weather scenario. Meteonorm is a parametric weather generator that extrapolates hourly data from statistical ones for any specific location. Where statistical data are not available, Meteonorm interpolates data from other nearby sites. Meteonorm is a combination of a climate database, a spatial interpolation tool and a stochastic weather generator, with global radiation data obtained from the Global Energy Balance Archive (GEBA). It allows the creation of typical years with hourly or minutely time resolution for any site (Remund et al., 1999). Moreover, Meteonorm allows to automatically transform current local data in future ones, according to future scenarios A2, A1B and B1 (three of IPCC ones) until 2100.

Finally, a Geographical Information System (GIS) tool is introduced into the process to support data collection through the use of codes at large scale, combining them and creating specific thematic maps.

The proposed methodology aimed at the assessment of energy impacts on occupied residential building stock generated by the variation of state of use and maintenance in adjacent built environment. Disuse and low state of maintenance participate in altering boundary conditions but they are features that usually not considered for the characterization of recurrent building types as well as for their interaction (De Fino et al., 2017; Fatiguso et al., 2015). The methodology here adopted follows the traditional process for interventions on existing building stock, consisting of the two phases of analysis and diagnosis. Both aimed at the systematic identification of representative characters for the in use residential buildings in historic districts, as well as the recognition of deficiencies and failures derived from previous abandonment process in the boundary. Moreover, aiming at the recognition of bioclimatic values of the traditional built environment, analysis should qualify and characterize all the subsystems of the envelope and the morphological asset of the subdistrict in which the residential stock is. Finally, the use of representative and homogeneous building types differently exposed to characters of use and state of maintenance offers the opportunity to determine classes of exposures and priorities in their management.

The methodological framework here adopted consists of three main phases:

1. The phase of analysis (knowledge) of the built environment at district scale and the taxonomy of recurrent features at scale of aggregate of buildings. The phase aims at the recognition of a limited number of building combinations representative of the district, according to the taxonomy of common features at recurrent building scale (Building type zero), as well as the combination of them considering the alteration of state of use and conservation (Building type combinations). In detail, the process of knowledge is characterized by two sub-phases:

a) analysis of the residential building stock, which aims at the identification of recurrent building types at district level. This analysis is the result of the characterization of morpho-distribution features at district scale and morpho-typologies, energy performances, construction techniques, and state of maintenance at building scale; 
b) analysis of the historic evolution and abandonment processes. Here, the taxonomy of levels for state of maintenance at the actual condition and transformations - both at building and district scale - during previous abandonment phase are the main elements of the knowledge. However, the sub-phase should be supported by a historiographic analysis focused on district development and historic urban plans that contributed in understanding recent transformations at district scale;

2. The phase of energy impact assessment offers the opportunity to test the residential heritage in relation to the abandonment and climate change phenomena. This is a diagnostic phase where the optimal condition is defined by the combination zero. Here, the building type is combined with representative local boundary conditions for states of use and maintenance. Moreover, it allows to predict future scenarios of energy impact, by considering only the variation of climate and the effect of the historic abandonment process. Aiming to these goals, two sub-phases are identified:

a) assessment of energy impacts derived from the parameters "state of use" and "state of maintenance". It is the results of a compared energy assessment between all the combinations resulting in phase $2 \mathrm{~b}$ and the combination zero. Local climate conditions derived from Meteonorm (Met_Act; format file .epw) are used and winter and summer consumptions are analysed separately;

b) assessment of future energy impacts where all the combinations are compared with the combination zero in the actual climate conditions. In this case, simulations use future climate data, referred to three different scenarios (Met_A2; Met_A1B; Met_B1, format file .epw);

3. The phase of identification of priority classes for energy impacts considering actual and future climate trends. In detail, the phase supports a first level of classification of risk exposure at district scale for residential buildings related to the only process of disuse and low level of maintenance, in a long-term perspective.

\section{CASE STUDY}

The previously described methodology has been applied to a specific case of study. The case of study selected is the old town center of Molfetta, a municipality located in Apulia region in the south of Italy. The case of study has been the object of previous energy assessment (De Tommasi et al., 2019), but it also allows to propose some findings related to the transformations that happened in the 1960s, and to the energy impact related to the current state of disuse of several buildings and to the slow process of recovery. The historic district of Molfetta is located in a peninsular area of city land and actually it represents a well bounded area. The case of Molfetta offered to the authors the possibility to discuss and enlarge several results because of its representativeness at region scale focus on prevalent materials and construction techniques, but it represents the critical case for suffered transformation during the $60 \mathrm{~s}$ in the whole South of Italy. In fact, the abandonment phase and the low state of maintenance generated critical loss on the district assessment creating open areas. Actually, the ancient core of Molfetta is regulated by the Recovery Plan enacted in 1994, which followed the previous one (dated back to 1977). The plan of 1977 highlighted the need to recover the hygienic, safety and static conditions of the district, aiming at the preservation of heritagelisted buildings, at the identification of buildings to recover, restore and demolish without reconstruction, at the definition of allowed actions of buildings' recovery, specifying technologies and materials, and finally at the identification of deficiencies in term of urban grid services to ensure at least the basic facilities, (e.g. electricity and gas supplies). Thanks to the first Recovery plan, most of buildings were recovered following the aesthetic and safety requirements, also using expropriation. However, some areas are still prioritising intervention in relation to the conservative state and the re-appropriation of places by the inhabitants.

According to the goals of methodology, the application aims at the assessment and the qualification of the whole district referring to the actual state, going beyond the normative thresholds of energy performances. Moreover, the method supports the relevance of the knowledge as first level of the analysis process focusing on the recognition of the significance of the place - as inherent bioclimatic properties -, and the ethical responsibility to preserve and re-activate the abandoned heritage.

\subsection{Knowledge of historic district and taxonomy of recurrent elements at the scale of building's aggregate.}

As a fundamental element of the knowledge of the actual state of built environment, the historic process of development in the ancient core of Molfetta was supported by the collection of archivist data. G. De Gennaro in "Storia ed Edilizia" (De Gennaro, 1977) and the actual Recovery plan were analysed as main documents because of their critical historical reconstruction of events. In detail, the first retraced the historic development of the ancient core, while the second focused on previous recovery plans and collected historic drawn of the development.

Focus on the historic development, first notices are referred to the Medieval period, during the XI and XIII centuries when few civil constructions and 2 churches were erected; during the same period, fortified city walls were built featured by an elliptical shape and two gateways that allow the entrance near the Castle (enter D in Figure 1) and the access from the main street that connected the city of Ruvo (an it ancient core of the Magna Graecia period located in the Apulia hinterland) to Molfetta called "Porta di Terra" (Gateway from the Land) (enter C in Figure 1). Outside and along these gateways, some magazines and productive buildings were built during the same period, while into the city walls, a big square existed for the urban market. Into the city walls 18 other buildings could be identified (Figure 1), assessed following the existent political, administrative and religious buildings and drawing the first street assess of the core (De Gennaro, 1977).

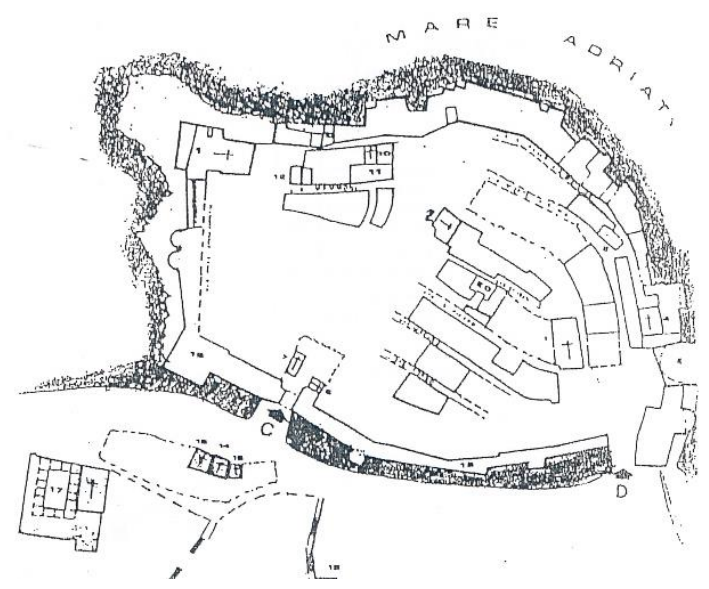

Figure 1. Development of historic district until medieval period. Source: Retrofit plan of historic district of Molfetta (1994). 
During the XIV-XV centuries, the Predominant Angioin period, the old core of Molfetta grown with a political and economic motivation to enrich the profits. During that period, some noble buildings were erected. As in Figure 2, urban arrangement continued following the previous phase (axis E-W); however, an early delimitation of $\mathrm{N}-\mathrm{S}$ axis could be recognised and the roman assessment - following "Cardo" and "Decumano" axis -were delated (De Gennaro, 1977). In 1529 Molfetta was plundered and its reconstruction featured the XVI and XVII centuries; moreover, buildings neighbouring the southern part of the city walls were built, above all noble ones. Along the northern part of city walls, residential buildings occupied the boundary. During the XVIII century most of squares and public spaces were occupied by buildings, while along the "Porta di Terra" gateway clearly defined the N-S axis. At the end of that century, the old core of Molfetta reached the maximum development (Figure 3).

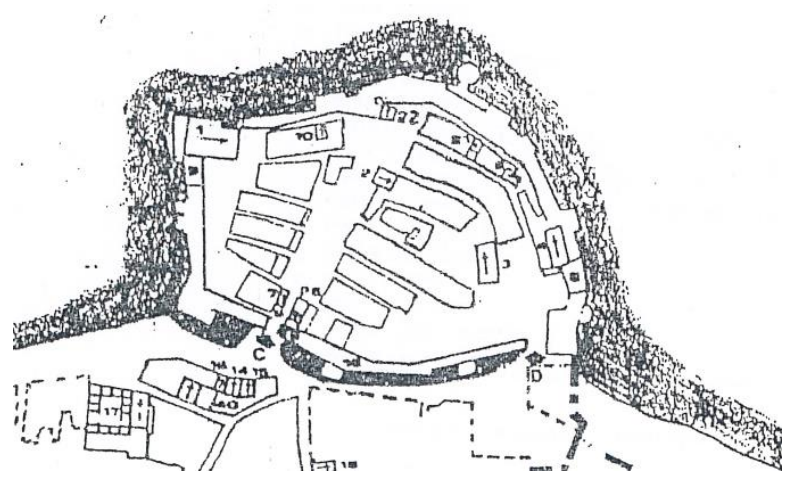

Figure 2. Development of historic district during the Angioin period. Source: Retrofit Plan of historic district (1994).

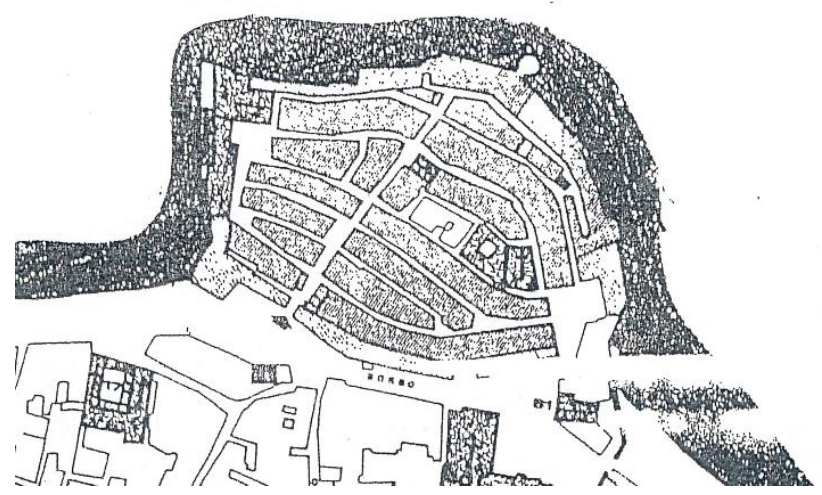

Figure 3. Maximum development of historic district at the end of XVIII century. Source: Retrofit plan of historic district (1994).

The old core of Molfetta was the object of three recovery plans during the period $1900-1935$. However, these plans included influences of previous experiences in Europe and Italy which characterized the previous century. In fact, the plans proposed the creation of new streets emphasizing two main lines: the inner street S-N that divided in two parts the core and the enlargement of another one in order to link the extremes along the E-W axis (Figure 4). Fortunately, no transformations were done and the original urban assessment was preserved, whereas recognition of urban district structure was identified.

At the end of the phase of knowledge at district scale, main morpho-distribution characters were identified. The district is assessed in long blocks ( $80-100 \mathrm{~m})$ with a width that varies from 16 to $18 \mathrm{~m}$; the blocks are distributed along the NNW-SSE axis in the core while, along borders, blocks follow the shape of the coast. Moreover, their width derived from the organization of buildings distributed in series and facing the streets whose are usually 2-4 $\mathrm{m}$ with the exception of NNE-SSW inner axis. Aiming to the characterization of buildings, all the characters of the whole district were analysed and properly codified for GIS tool, focus on the only residential buildings (private and public) while, listed buildings in national regulations (e.g. Law 1089/1939) were excluded. Referring to the morpho-typologies, the Palace and the Tower Houses represent the existent types. However, the taxonomy of data highlighted that the latest one is the most representative (75\%) (Figure 5). Moreover, also considering the asset of blocks, the prevalent type of Tower House is a middle unit (Figure 5) (Middle Tower unit 66\%).

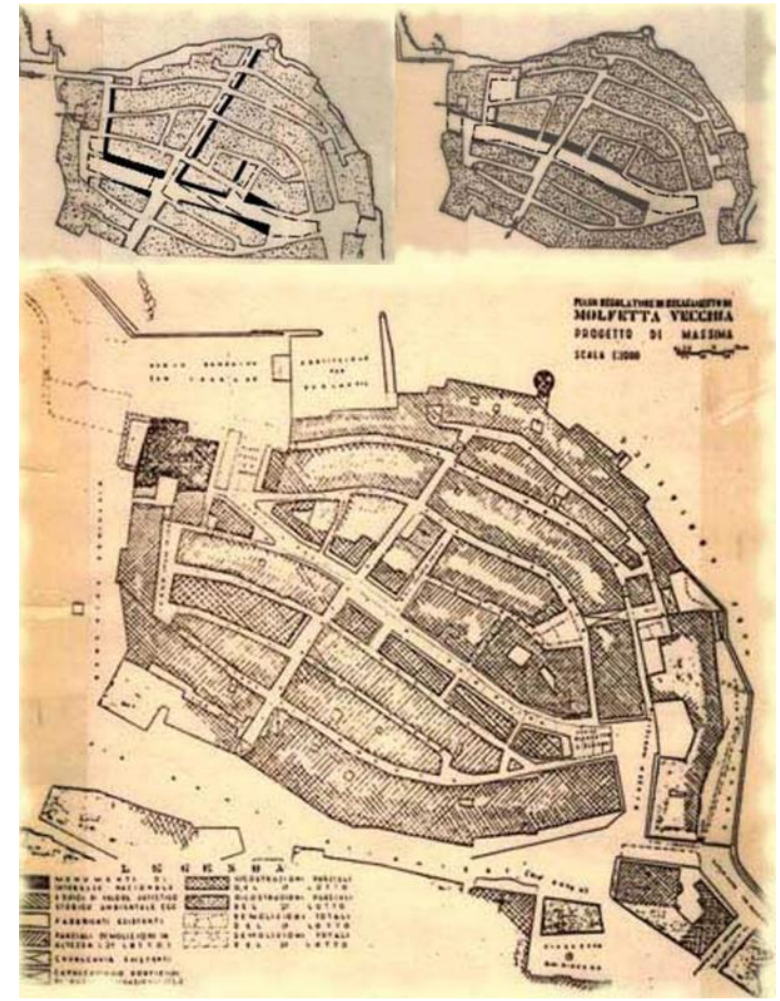

Figure 4. Drawn of proposed variation of street asset during 1900-1930. Source: Retrofit plan of historic district (1994)

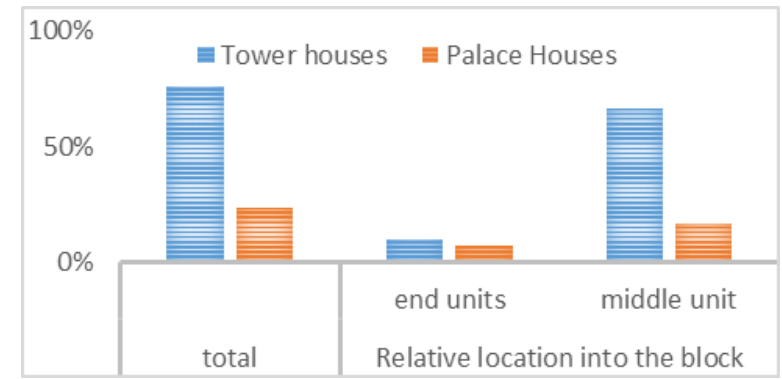

Figure 5. Analysis of morpho-typology of buildings

The Tower House has a prevalent vertical development, presenting three residential levels (upper floors) and a commercial one at the ground floor. Focus on the construction characters, towers have a structure based on compound thick walls (plastered or unplastered varying from 75-100 $\mathrm{cm}$ ), residential inner floors are made by wooden beams, while at the ground floor commercial space is divided by the residential one by a calcareous vault. Finally, the wooden roof - lacking in 
insulation - could be featured by bituminous waterproofing (if maintainable) or calcareous paving (called "chiancarelle" if accessible). As result of codification, combination and taxonomy of all characters, Table 1 details the main combination of features at Tower House scale, defining the Building type zero; thermal properties for each sub-system of the envelope were calculated. It is necessary specify that external finishing layers were not introduced in the analysis (e.g. variation of albedo value for different materials on roofs and outside the walls) because of the main aim of the analysis. That kind of analysis allows to focus on the main construction technique for each sub-system and so on the medium value of thermal transmittance.

\begin{tabular}{|c|c|c|c|}
\hline $\begin{array}{c}\text { Building } \\
\text { Type Zero } \\
\left(\text { Bt }_{\text {zero }}\right)\end{array}$ & Sub-System & $\begin{array}{c}\text { Thickness } \\
{[\mathrm{m}]}\end{array}$ & $\begin{array}{c}\text { Thermal } \\
\text { Conductance } \\
{\left[\mathrm{W} / \mathrm{m}^{2} \mathrm{~K}\right]}\end{array}$ \\
\hline \multirow{2}{*}{$\begin{array}{c}\text { Middle } \\
\text { Tower } \\
\text { House }\end{array}$} & Walls & 0,8 & 2 \\
\cline { 2 - 4 } & Windows & - & 5,4 \\
\cline { 2 - 4 } & Roof & 0,17 & 2,83 \\
\cline { 2 - 4 } & Ground floor & 0,08 & 1,83 \\
\hline
\end{tabular}

Table 1. Thermal performances of the envelope in the Building type zero $\left(\mathrm{Bt}_{\mathrm{zero}}\right)$

However, during the 1930s the old core was featured by a prominent level of bad state of conservation. This state was the result of the absence of a recovery plan and, consequently, several and uncontrolled transformations - e.g. creation of a new higher floor -. These actions caused a serious statically decay for a wide percentage of buildings in the urban core until the 1964 when the collapse of a building caused three victims. That extreme event was the first of several ones that caused the loss of some parts of the historic core of Molfetta, highlighting also the socio-economic impossibility of inhabitant to recover buildings. At the actual state, the traumatic event could be read into the district as the creation of:

- "close garden" that identifies a public space enclosed in the boundary walls at ground floor of collapsed buildings; there are three gardens and dimensions vary with the extension of the damaged zone. Despite the term "garden", they are paved surfaces with low percentage of pervious surfaces. However, that sub-district solution contributes to the preservation of the original asset;

- paved square, deleting part the block and enlarging the front of nearest blocks; in that option, Amente Square is the only case created.

Near to that and focusing to the actual state, the ancient core is featured by the signs of " 60 s because of the presence of abandoned buildings as well as residential units featured by low state of maintenance, living in close contact with occupied ones. Moreover, some recurrent elements of the state of maintenance for unoccupied buildings could be described in term of:

a. a medium state of conservation referring to the construction and materials preservation levels at building scale (presence of roofs and original wooden windows);

b.a low state where windows and roof were disrupted (absent).

Because of the high relevance of tower house, only the cases of middle tower units were discussed in recognition of recurrent building types. Here, the variation in state of maintenance and use for building type zero were introduced recognizing all the variations:
- Bt.a changes from the zero condition $\left(\mathrm{Bt}_{\mathrm{zero}}\right)$ for the only state of use;

- Bt.b varies from the representative unit changing conditions both for state of dis-use and low state of maintenance.

In detail of data collection, figure 6 shows the Building type combinations and their position according to the district variations during ' 60 s (gardens and square).

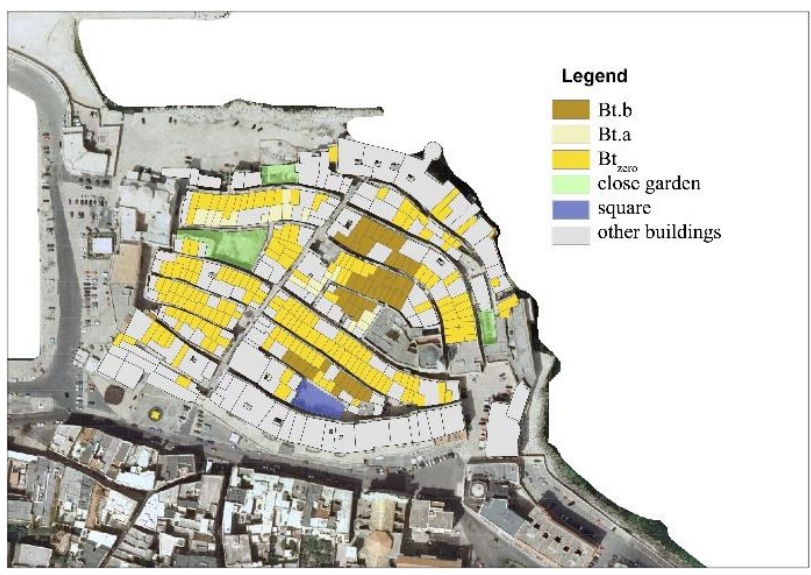

Figure 6. Map of the building type variation referred to states of use and maintenance and map of district transformations.

\begin{tabular}{|c|c|c|c|c|c|c|}
\hline \multirow{2}{*}{ 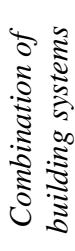 } & \multirow{2}{*}{ 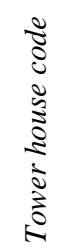 } & \multirow{2}{*}{ 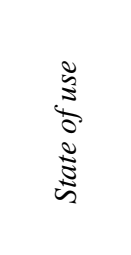 } & \multirow{2}{*}{ 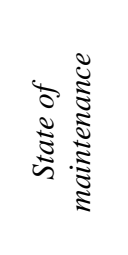 } & \multirow{2}{*}{ 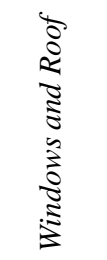 } & \multicolumn{2}{|c|}{$\begin{array}{l}\text { Exposure } \\
\text { front }\end{array}$} \\
\hline & & & & & $\begin{array}{l}\overrightarrow{0} \\
\overline{0} \\
\bar{z} \\
z\end{array}$ & $\begin{array}{l}\tilde{\Xi} \\
\vdots \\
\vdots \\
\vdots \\
\vdots \\
\vdots\end{array}$ \\
\hline \multirow{2}{*}{$\mathrm{C} 1$} & $\mathrm{Bt}_{\text {zero }}$ & Occupied & Medium & Present & \multirow{2}{*}{$\mathrm{C}_{\text {zero }}$} & \multirow{2}{*}{$\mathrm{C} 1 \mathrm{~b}$} \\
\hline & Bt $_{\text {zero }}$ & Occupied & Medium & Present & & \\
\hline \multirow[b]{2}{*}{$\mathrm{C} 2$} & $\mathrm{Bt}_{\text {zero }}$ & Occupied & Medium & Present & \multirow[b]{2}{*}{$\mathrm{C} 2 \mathrm{a}$} & \\
\hline & Bt.a & $\begin{array}{c}\text { Un- } \\
\text { occupied }\end{array}$ & Medium & Present & & \\
\hline \multirow[b]{2}{*}{$\mathrm{C} 3$} & $\mathrm{Bt}_{\text {zero }}$ & Occupied & Medium & Present & \multirow[b]{2}{*}{$\mathrm{C} 3 \mathrm{a}$} & \multirow[b]{2}{*}{$\mathrm{C} 3 \mathrm{~b}$} \\
\hline & Bt.b & $\begin{array}{c}\text { Un- } \\
\text { occupied }\end{array}$ & Low & Absent & & \\
\hline
\end{tabular}

Table 2. Combination of building systems and description of building types in term of states of use and maintenance and exposure

At the end of analysis, five Building type combinations were defined, where 3 of them depend by the adjacency of different state of use; those were combined with the presence of open areas in front through the codification of properties in GIS database. In detail of results of combinations (Table 2):

- in $\mathrm{C} 1$ the Building type zero $\left(\mathrm{Bt}_{\mathrm{zero}}\right)$ is located near an homogeneous one in term of construction and material technics, state of use and state of maintenance $\left(\mathrm{Bt}_{\text {zero }}\right)$; however, buildings should be located facing a narrow street (a) or an open area (b); in detail, $\mathrm{C}_{\text {zero }}$ is representative of the original asset of district and it concerns the combination of two Building type zero, representing the Combination zero; 
- in $\mathrm{C} 2$ the Building type zero $\left(\mathrm{Bt}_{\mathrm{zero}}\right)$ is located near a homogeneous one in term of construction and material technics and state of maintenance, while it differs for its state of dis-use (Bt.a); in that case, both buildings should be located just facing a narrow street (a);

- in $\mathrm{C} 3$ the Building type zero $\left(\mathrm{Bt}_{\text {zero }}\right)$ is placed near an homogeneous one just in term of construction and material technics, while it differs for state of maintenance and its state of dis-use (Bt.a); as in the first combination, both buildings should be located facing a narrow street (a) or an open area (b).

\subsection{Assessment phase of energy impacts}

The Building type were modelled in DesignBuilder ${ }^{\circledR}$ using construction and material details recognized in previous phase. Moreover, the combinations were modelled using a system of two building types (Table 1) and specific variations for the characterization of boundary conditions:

- systems in $\mathrm{C} 1$ were determined using 2 identic models for geometric and performance characters of the envelope, as well as energy systems and residential program uses;

- in $\mathrm{C} 2$ buildings were modelled in an equivalent way for geometric and performance characters while differ in energy systems and program uses; here, just one was featured by an active program use and energy systems, in order to properly model one building as unoccupied;

- in $\mathrm{C} 3$ the system of buildings followed the case $\mathrm{C} 1$ just for geometric features; here, the unoccupied state for one of the building systems followed the measures of $\mathrm{C} 2$ while the state of maintenance was modelled delating roof and windows.

Focus on the physic boundary conditions of the context, the couples of Building types were introduced in adjacency of a system of built environment (having adiabatic character along the nearest walls) featured by same construction and materials elements of modelled buildings. It was functional in modelling canyon; in fact, the construction of a $2 \mathrm{~m}$ width canyon - using an on-face block featured by similar optical characters of the building type and in-front block - became representative of boundary conditions at canyon scale. Finally, the system was rotated following the prevalent exposition of $+20^{\circ}$ on E-W axis.

The energy assessment derived from the dynamic thermal simulations at hourly time-steps, considering actual and future climates and according to the goals of that phase. In detail of data, Met_Act and A2_2050, A1B_2050, B1_2050 .epw files contained the statistical climate data referred to actual and local conditions and likely-future scenarios.

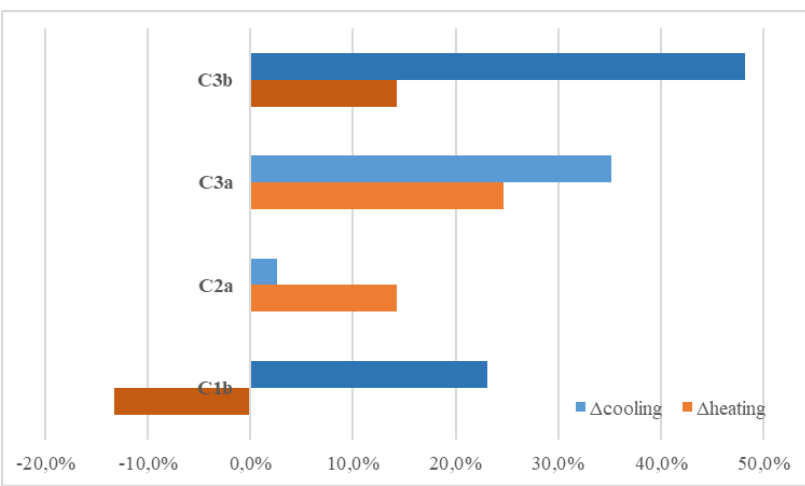

Figure 7 - Comparative assessment of energy impacts comparing building type combinations to zero one $\left(\mathrm{C}_{\mathrm{zero}}\right)$
Discussing the energy assessment of type combinations (Table 2) in actual climate conditions (Met_Act), Figure 7 reports the percentages of energy variations comparing all the combination with the zero one $\left(\mathrm{C}_{\text {zero }}\right)$.

In detail of results, three major effects - as energy impact on the occupied residential built - are highlighted:

1. focus on the impact on dis-use parameter (C2a), just wintry consumptions are affected $(+14 \%)$ as the direct consequence of increasing energy loss along wall that dividing residential units;

2. evaluating the adjacency to building with different state of maintenance and use (C3a), the type was affected both in summer and winter consumption $(+25 \%$ and $+35 \%$, respectively); here, the tower house could be associated to an end unit (Fatiguso et al., 2015);

3. finally, the loss of the physical boundary conditions derived from the disruption of part of in-front block highlighted a mean condition in energy assessment; in fact, with the direct comparison in $\mathrm{C} 1 \mathrm{~b}$, wintry energy variation $(-13 \%)$ derived from the positive effect of solar energy exposure while it constituted a major affection in summer $(+23 \%)$. Similarly, the energy (negative) impact on tower house in $\mathrm{C} 3 \mathrm{~b}$ derived by the summer increasing consumptions $(+48 \%)$.

After the first assessment, it is clear that energy impacts on that residential built should be amplified in future climate conditions coherently with the IPCC scenarios.

Following the same approach, Figure 8 reports the assessment of future energy impacts on the occupied residential buildings, as the direct comparison between Combination types - in future scenarios - and zero one ( $\left.\mathrm{C}_{\text {zero }}\right)$ at the actual conditions (Met_Act).

Discussing the impacts on the Tower house type derived from the loss of in-front block (Combinations $b$ ) in future climate exposures, as well as from the adjacency to unoccupied buildings (C2a) or featured by low state of maintenance (C3a), the summer emergency should be read. In fact, independently from the type of scenarios, the unbalance has a growing tendency focusing on reductions of wintry consumption - as the consequence of growing temperatures - and increasing of summer ones, having the maximum values of exposure in $\mathrm{C} 3 \mathrm{~b}(+170 \%$ and $+157 \%$ in $\mathrm{A} 1 \mathrm{~b}$ e A2 scenarios, respectively).

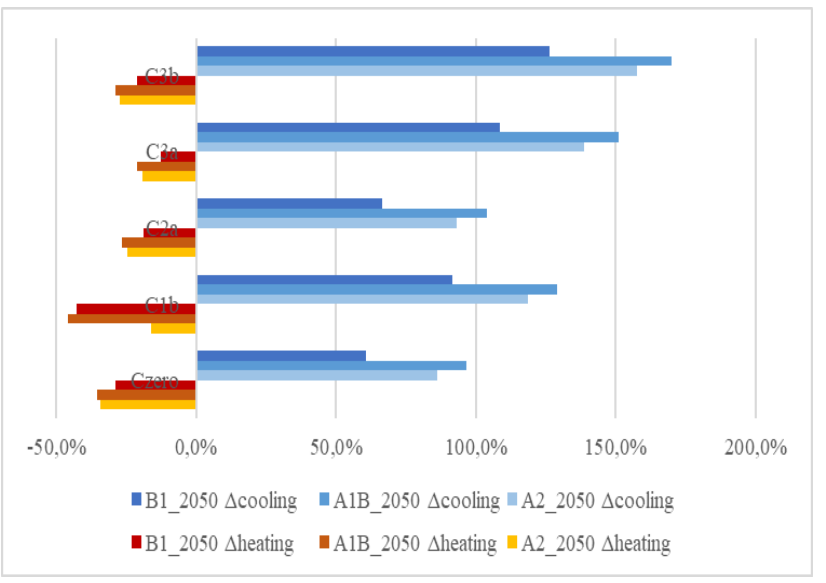

Figure 8 - Comparative assessment on energy impacts comparing Building type combinations in future scenario to Combination zero $\left(\mathrm{C}_{\text {zero }}\right)$ at actual climate condition (Met_Act) 
In a wider scope, the process supports the assessment of energy impacts in inhabited building quote caused by the slow processes of abandonment and recovery.

After all, a limited number of classes of priority for in-use built environment (Building Type zero) in different combinations could be defined, as well as the efficacy of interventions both in buildings to recovery and already in use.

\subsection{Identification of classes of priorities for energy impacts}

The codification of parameters state of use and level of conservations at building type zero scale in GIS systems and the qualification of their responsibilities in energy impacts allow the identification of homogeneous classes of priorities for the analysed heritage. In detail, for each building type zero, combined in couple as in Table 2, was assigned a priority level using a code varying between 0 and 4 as the descriptor parameter of energy impact for the critical regime, the summery one (Table 3). Zero value was associated to the not-influent building, the building type in the combination zero, while the maximum one to the same building in the combination featured by the major energy impact, as the $\mathrm{C} 3 \mathrm{~b}$. The codification should take in account variations that could occur evaluating actual and future scenarios. In the specific case of the historic built environment of Molfetta, no variations were observed between impacts at the actual conditions and future scenarios.

Finally, combining information and implementing the database in GIS with scores, the whole district was mapped with the levels of priorities (Figure 9).

\begin{tabular}{|c|c|c|c|c|c|}
\hline & Met_Act & $A 2 \_2050$ & $A 1 B \_2050$ & $B 1 \_2050$ & Score \\
\hline$C_{\text {zero }}$ & $0 \%$ & $86,3 \%$ & $96,5 \%$ & $60,7 \%$ & 0 \\
\hline$C 2 a$ & $4 \%$ & $93,3 \%$ & $103,8 \%$ & $66,6 \%$ & 1 \\
\hline$C 1 b$ & $17 \%$ & $118,6 \%$ & $129,1 \%$ & $91,5 \%$ & 2 \\
\hline$C 3 a$ & $28 \%$ & $138,8 \%$ & $151,2 \%$ & $108,6 \%$ & 3 \\
\hline$C 3 b$ & $38 \%$ & $157,7 \%$ & $170,0 \%$ & $126,4 \%$ & 4 \\
\hline
\end{tabular}

Table 3 - Score of priority on cooling impact for Building type zero evaluated in the combinations of buildings

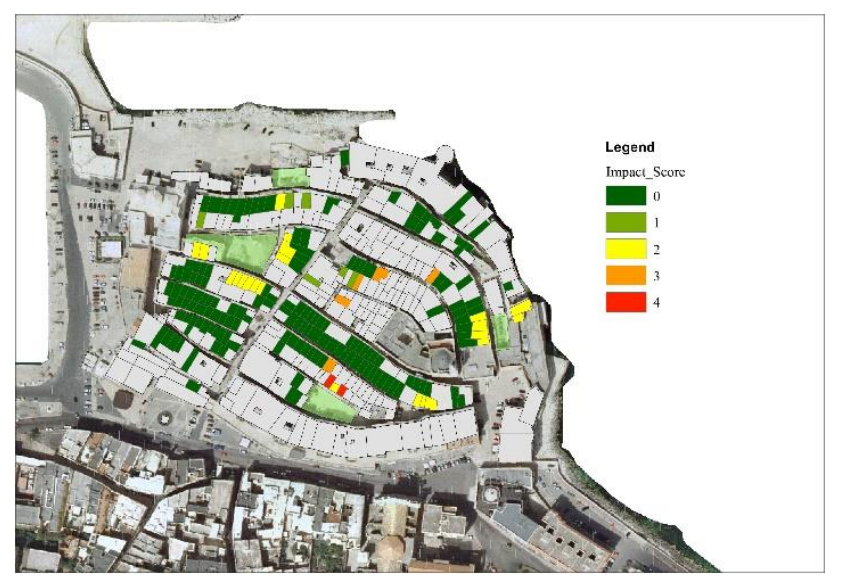

Figure 9 - Map of priority in energy impact evaluated for Building type zero

\section{CONCLUSION}

The necessity to reduce energy consumptions in the residential building stock encouraged previous activities both in technical and scientific fields. However, the recognition of critical parameters of energy performances in the architectural heritage moved the scientific community through specific methodologies useful for the recognition of critical elements and peculiarities, the identification of priority solutions and the validation of them coherently with technical and formal values. It is true that the landscape value (historic unicum) for buildings arranged in historic districts cannot forget the relations between single buildings, as well the historic processes of transformations and abandonment of some parts that represent an open discussion for their management at district scale until now.

In that framework, the presented paper aimed to define a proper system of instruments and processes useful for the assessment of energy impacts on actual occupied dwellings derived from the presence of uninhabited ones and/or in low state of conservation, as well as derived from previous critical events (e.g. disruption of some parts of the historic district). The process is a systemic approach based on the relevance of knowledge and the assessment of energy impacts derived from the analysis and diagnosis phases of the traditional recovery process for cultural heritage.

The complexity in managing all the parameters involved in the problem was solved applying and validating the proposed methodology to a representative case study in the Apulia region. In fact, the ancient core of Molfetta is featured by the high compactness of typical historic district in Mediterranean area and it suffered the crisis phase of $60 \mathrm{~s}$ where most dwelling were abandoned and some part of districts collapsed for low level of maintenance.

The phase of knowledge, aimed at the recognition of previous transformation processes, represents the main instrument for the identification of the nature of energy impacts. In fact, the quantification of increased consumptions in dwelling located near the transformed areas is the opportunity to test the building systems in open areas where now historic and cultural damn cannot be read. It is necessary to underline that, moved from the will to reach a wider assessment process in solving the reduction of impacts through mitigation actions and solution safeguarding socioeconomic, socio-cultural and environmental values of historic districts, the described process is implementable with impacts derived from other inner features (volumetric transformations, substantial variation of sub-systems of the envelope, change in use, etc.) or outer the building structures (interferences for changing paving in squares), as well as other kind of risk exposures (e.g. earthquake, landslide). In addition, GIS supports the implementation of all the results, the graphical distribution of exposure levels and their combinations in a multi-risk point of view.

Finally, despite the presentation of an only case study for shortness, discussed results represent an introductive share in risk managing into a wider profile of analysis and diagnosis for historic districts that should involve the emergency in climate change and the necessities to operate in classes of priority also in an interdisciplinary methods for their managing.

\section{ACKNOWLEDGEMENTS}

The authors would like to acknowledge the Italian Ministry of Education, University and Research (MIUR) for supporting and funding the research under the project AIM1871082 - 1" in the AIM PROGRAM (Attrazione e Mobilità Internazionale). 


\section{REFERENCES}

Bhandari, P., 2015: Asia: climate change battleground. In Climate2020. https://www.climate2020.org.uk/wpcontent/uploads/2015/06/BHANDARI-CLIMATE2020.pdf

Cannarozzo, T., 2007: Centri storici come periferie: il caso del centro storico di Palermo, tra eccellenza e marginalità. Conferenza INU “Territori e Città Del Mezzogiorno:"Quali Periferie.

Castellari, S., Venturini, S., Giordano, F., Ballarin Denti, A., Bigano, A., Bindi, M., Bosello, F., Carrera, L., Chiriacò, M.V, Danovaro, R., 2014: Elementi per una Strategia Nazionale di Adattamento ai Cambiamenti Climatici. Ministero Dell'Ambiente e Della Tutela Del Territorio e Del Mare, Roma.

Coppola, E., Giorgi, F., 2010: An assessment of temperature and precipitation change projections over Italy from recent global and regional climate model simulations. 32(February 2009), 11-32. https://doi.org/10.1002/joc

Correia, M., Dipasquale, L., Mecca, S., 2014: VERSUS: Heritage for Tomorrow (M. Correia, L. Dipasquale, \& S. Mecca (eds.)). Firenze University Press.

De Fino, M., Scioti, A., Cantatore, E., Fatiguso, F. 2017: Methodological framework for assessment of energy behavior of historic towns in Mediterranean climate. Energy and Buildings, 144, 87-103. https://doi.org/10.1016/j.enbuild.2017.03.029

De Gennaro, G., 1977: Storia ed Edilizia (pp. 277-303). Archivio Storico Pugliese.

De Tommasi, G., Fatiguso, F., De Fino, M., 2019: Riqualificazione energetica del patrimonio edilizio storico. Studi per il geocluster dei borghi antichi in area mediterranea. Edicom Edizioni.

Diappi, L., 2009: Rigenerazione urbana e ricambio sociale. Franco Angeli.

EPBD, 2010: 31/EU of the European Parliament and of the Council of 19 May 2010 on the energy performance of buildings. European Commission.

European Commission, 2013: An EU strategy on adaptation to climate change. [S1]: European Commission.

Falini, P., 1978: I centri storici; politica urbanistica e programmi di intervento pubblico: Bergamo, Bologna, Brescia, Como, Gubbio, Pesaro, Vicenza.

Fatiguso, F., Cantatore, E., De Fino, M., 2016: Strategies for energy retrofitting of historic urban districts. Progress in Industrial Ecology, 10(4). https://doi.org/10.1504/PIE.2016.083909

Fatiguso, F., De Fino, M., Cantatore, E., 2015: An energy retrofitting methodology of Mediterranean historical buildings. Management of Environmental Quality, 26(6). https://doi.org/10.1108/MEQ-04-2015-0051

Fatiguso, F., De Fino, M., Cantatore, E., Caponio, V., 2017: Resilience of Historic Built Environments: Inherent Qualities and Potential Strategies. Procedia Engineering, 180. https://doi.org/10.1016/j.proeng.2017.04.262

Gotham, K.F., Faust, M., 2020: Antagonisms of Adaptation: Climate Change Adaptation Measures in New Orleans and New York City. In Louisiana's Response to Extreme Weather (pp. 93112). Springer.
Grafakos, S., Viero, G., Reckien, D., Trigg, K., Viguie, V., Sudmant, A., Graves, C., Foley, A., Heidrich, O., Mirailles, J.M., 2020: Integration of mitigation and adaptation in urban climate change action plans in Europe: A systematic assessment. Renewable and Sustainable Energy Reviews, 121, 109623. Guillaud, H., 2014: Socio-cultural sustainability in vernacular architecture. In M. Correia, L. Dipasquale, \& S. Mecca (Eds.), VERSUS: Heritage for Tomorrow (pp. 49-55). Firenze University Press.

ICOMOS, 2011: The Valletta Principles for the Safeguarding and Management of Historic Cities, Towns and Urban Areas. Paris: UNESCO. http://www.icomos.org.tr/Dosyalar/ICOMOSTR_ 0209751001353671440.pdf

Mohajerani, A., Bakaric, J., Jeffrey-Bailey, T., 2017: The urban heat island effect, its causes, and mitigation, with reference to the thermal properties of asphalt concrete. Journal of Environmental Management, 197, 522-538.

Nakicenovic, N., Alcamo, J., Grubler, A., Riahi, K., Roehrl, R.A., Rogner, H.H., Victor, N., 2000: Special Report on Emissions Scenarios (SRES), A Special Report of Working Group III of the Intergovernmental Panel on Climate Change. Cambridge University Press.

Parry, M.L., 2007: Climate change 2007-impacts, adaptation and vulnerability: Working group II contribution to the fourth assessment report of the IPCC (Vol. 4). Cambridge University Press.

Remund, J., Kunz, S., Lang, R., 1999: METEONORM: Global meteorological database for solar energy and applied climatology. Solar Engineering Handbook, version 4.0, Bern, Meteotest. Meteotest, Bern.

Santamouris, M., Synnefa, A., Karlessi, T., 2011: Using advanced cool materials in the urban built environment to mitigate heat islands and improve thermal comfort conditions. Solar Energy, 85(12), 3085-3102.

Steynor, A., Leighton, M., Kavonic, J., Abrahams, W., Magole, L., Kaunda, S., Mubaya, C.P., 2020: Learning from climate change perceptions in southern African cities. Climate Risk Management, 27, 100202.

Troi, A., 2011: Historic buildings and city centres-the potential impact of conservation compatible energy refurbishment on climate protection and living conditions. Proceedings of the Conference Energy Management in Cultural Heritage. Dubrovnik (Croatia).

Tyler, S., Moench, M., 2012: A framework for urban climate resilience. Climate and Development, 4(4), 311-326.

Walker, B., Holling, C. S., Carpenter, S., Kinzig, A., 2004: Resilience, adaptability and transformability in social-ecological systems. Ecology and Society, 9(2).

Yun, G.Y., Ngarambe, J., Duhirwe, P.N., Ulpiani, G., Paolini, R., Haddad, S., Vasilakopoulou, K., Santamouris, M., 2020: Predicting the magnitude and the characteristics of the urban heat island in coastal cities in the proximity of desert landforms. The case of Sydney. Science of The Total Environment, 709, 136068 